\title{
METHYLPHENIDATE INDUCED ECCHYMOSIS
}

\author{
Ebru Şahan ${ }^{1} \&$ Muhammed Emin Boylu ${ }^{2}$ \\ ${ }^{1}$ Department of Psychiatry, Marmara University, Istanbul, Turkey \\ ${ }^{2}$ Department of Psychiatry, Bezmialem Vakuf University, Istanbul, Turkey
}

received: 29.10.2020;

revised: 18.12.2020;

accepted: 28.12 .2020

$* * * *$

\section{INTRODUCTION}

Methylphenidate is a psychostimulant drug indicated in attention deficit hyperactivity disorder (ADHD) and narcolepsy (Connor et al. 2000). The most common side effects include difficulty in falling asleep, decreased appetite, abdominal pain, blurred vision, nausea, tremor, dizziness, and headache (Stahl 2014). As far as we know, methylphenidate has not been associated with ecchymosis before in the literature.

\section{CASE REPORT}

A 30-year-old female patient with complaints of inability to concentrate when someone is talking, impatience for listening, restlessness, startling, getting bored quickly, striving to stay throughout her examinations and fear of failure was admitted. She was also worried about if she could express herself correctly. Generalized Anxiety Disorder was prioritized and escitalopram 5 $\mathrm{mg}$ /day was prescribed.

In the second interview, her attention deficit was prominent, motor hyperactivity was low and no sign of impulsivity was observed. In neuropsychological tests, the abstract thinking ability was impaired, the amount of semantic and lexical fluency was significantly below the norm values, cognitive dysfunction was present and her profile was consistent with the distraction. It was suspected that the patient's inattention was caused by ADHD, not anxiety. Furthermore, she did not benefit from escitalopram $5 \mathrm{mg}$ /day so it was discontinued on day three. ADHD-inattentive type was considered and $18 \mathrm{mg}$ /day osmotic release oral system (OROS) methylphenidate was started. She had waited for ten days to use and the following day taking methylphenidate, she noticed a $3 \times 2 \mathrm{~cm}$ bruise on the inferior part of her right gluteal region, lateral to the proximal thigh (Figure 1).

She denied any trauma, crush or compression, she did not feel any pain. She had no history of hypertension, bleeding disorder, or any other disease. Recently, she did not take acetylsalicylic acid, nonsteroidal anti-inflammatory drugs (NSAIDs), warfarin or any antiplatelet drugs. She was not using alcohol or any other substance.

Laboratory test results were platelet count 194.000 / uL (142.000-424.000 / uL), PT: $12.6 \mathrm{sec}(10.8-15.3 \mathrm{sec})$, aPTT: $31.9 \mathrm{sec}(24-42 \mathrm{sec})$, INR: 0.96 (0.8-1.2). Hemogram, hepatic and renal function tests were all within normal limits. The internal medicine consultation revealed

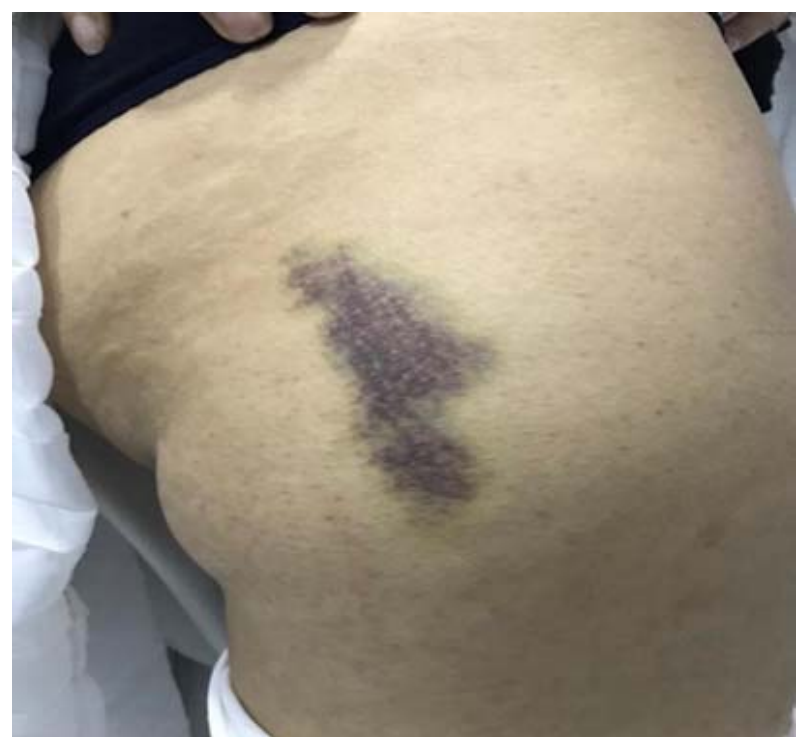

Figure 1. Bruise on the inferior part of right gluteal region one day after the use of methylphenidate

no organic etiology causing ecchymosis. A drug-related cause was suspected and OROS-Methylphenidate was discontinued. Then, her ecchymosis regressed and did not reoccur. She did not consent for similar drug treatments (immediate-release methylphenidate, atomoxetine, etc.) and was referred to a therapist.

\section{DISCUSSION}

Methylphenidate is used effectively in the treatment of attention deficit hyperactivity disorder (ADHD), conduct disorder and narcolepsy (Connor et al. 2000). The most common side effects of methylphenidate are difficulty in falling asleep, decreased appetite, abdominal pain, blurred vision, nausea, tremor, dizziness and headache. In addition to these, less frequent side effects include hallucinations, excessive sensuality or inappropriate sexual behavior, skin rashes, obsessive-compulsive symptoms, gynecomastia, painful muscle cramps and hyperhidrosis.

In this case, the causality between methylphenidate and ecchymosis was assessed with Naranjo Adverse Drug Reaction Probability Scale (Naranjo et al. 1981). Although the literature on methylphenidate related ecchymosis is bare, there are some case reports showing that it may cause epistaxis (Avcil 2017, Chandradasa \& Rathnayake 2019), hypermenorrhea or polymenorrhea (Coskun \& Adak 2017) (1 point). 
Ecchymosis occurred one day after the initiation of medication (2 points). Ecchymosis regressed when the drug was discontinued (1 Point). There were no likely factors to cause this reaction other than the drug (2 points). The total score of our case was 6 points which means probable.

Although the temporal relationship was evident between the methylphenidate and ecchymosis, exact mechanisms remain uncertain. Methylphenidate may have acted on platelet functions via catecholamines, increasing norepinephrine (NE) and dopamine (DA) by blocking their reuptake (Stahl 2014).

Norepinephrine induces intravascular platelet aggregation (Haft et al. 1972) yet various effects of dopamine on platelet aggregation have been described. Braunstein et al. incubated human platelet-rich plasma (PRP) in an aggregometer for 120 seconds at 37 degrees C, with either dopamine or saline control. They added Adenosine diphosphate (ADP), epinephrine or collagen as the aggregating agent. Dopamine inhibited the induction of platelet aggregation by all three agents and caused platelet disaggregation. However, at low doses $(40 \mathrm{~m} \mu \mathrm{g} / \mathrm{ml}$ or less) dopamine-induced platelet aggregation, enhanced ADPinduced aggregation and inhibited epinephrine aggregation. They argued that dopamine may exert its effects via the platelet membrane (Braunstein et al. 1977).

Anfossi et al. (1992) hypothesized that the effects on both the aggregation and potentiation of the platelet response to other agents are dependent on interactions of dopamine mainly with platelet alpha2-adrenoceptors. Nevertheless, in subjects who exhibited a dopamine-induced secondary aggregation, dopamine receptors could be involved in platelet activation (Anfossi et al. 1992).

Schedel et al. suggested that dopamine was an ADPdependent platelet coagonist which acted via D2-like but not D1-like or adrenergic receptors. They observed the specific DAT antagonists methylphenidate $(\mathrm{MPh}, 10$ $\mu \mathrm{M})$ and cocaine (Coc, $1 \mu \mathrm{M})$ did not inhibit the DA coagonism on platelets and concluded this was because they did not work on D2-like receptors (Schedel et al. 2008).

In the absence of other medical reasons that may explain this side effect, a possible causal link between methylphenidate and ecchymosis can be established chronologically. The exact mechanisms are unkown different platelet response patterns to different dopamine concentrations and individual sensitivity to this catecholamine may be the possible explanations. We believe that presentation of such rare side effects is important for clinicians, because if stimulants are shown to inter fere with platelet function in more patients, the routine monitoring of platelet count and function in patients treated with methylphenidate may be considered. Besides, unexpected reactions may strongly affect the patient's therapeutic compliance and leave their ADHD untreated or suboptimally treated as in our case.

Written informed consent has been taken from the patient for publication of article and photo of the lesion with scientific purposes.

\section{Acknowledgments: None.}

\section{Conflict of interest: None to declare.}

\section{Contribution of individual authors:}

Ebru Şahan: study conception and design, acquisition of case history, analysis and interpretation of data, drafting and revision of the manuscript;

Muhammed Emin Boylu: study conception and design, acquisition of case history, drafting of the manuscript.

\section{References}

1. Anfossi G, Massucco P, Mularoni E, Cavalot F, Burzacca $S$, Mattiello L et al.: Studies on the effect of dopamine on the human platelet response. Clin Exp Pharmacol Physiol 1992; 19: 613-618

2. Avcil S: Nasal bleeding probably associated with methylphenidate. J Child Adolesc Psychopharmacol 2017; 27: 924-925

3. Braunstein KM, Sarji KE, Kleinfelder J, Schraibman HB, Colwell JA \& Eurenius $K$ : The effects of dopamine on human platelet aggregation, in vitro. $J$ Pharmacol Exp Ther 1977; 200:449-457

4. Chandradasa $M$ \& Rathnayake LC: Immediate-Release Methylphenidate-Associated Recurrent Nasal Bleeding in Siblings. J Clin Psychopharmacol 2019; 39:284-285

5. Connor DF, Barkley RA \& Davis HT: A pilot study of methyiphenidate, clonidine, or the combination in ADHD comorbid with aggressive oppositional defiant or conduct disorder. Clin Pediatr (Phila) 2000; 39:15-25

6. Coskun $M \&$ Adak I: Excessive and frequent menstrual bleeding with methylphenidate in an adolescent girl with attention-deficit hyperactivity disorder. J Clin Psychopharmacol 2017; 37: 637-639

7. Haft JI, Kranz PD, Albert FJ \& Fani K: Intravascular platelet aggregation in the heart induced by norepinephrine: microscopic studies. Circulation 1972; 46:698-708

8. Naranjo C, Busto U, Sellers E, Sandor P, Ruiz I \& Roberts EA: Naranjo ADR probability scale. Clin Pharmacol Ther 1981; 30:239-245

9. Schedel A, Schloss $P$, Klüter $H \&$ Bugert P: The dopamine agonism on ADP-stimulated platelets is mediated through D2-like but not D1-like dopamine receptors. NaunynSchmiedebergs Arch Pharmacol 2008; 378:431-439

10. Stahl SM: Stahl's essential psychopharmacology: Prescriber's Guide. Cambridge University Press, 2014

\section{Correspondence:}

Ebru Şahan, $M D$

Department of Psychiatry, Marmara University

Fevzi Çakmak Mah, Muhsin Yazıcıoğlu Cad. No:10 P.K.34899 Pendik, İstanbul, Turkey

E-mail:ebrushaan@hotmail.com 